\title{
Communal child-rearing: The role of nurses in school health
}

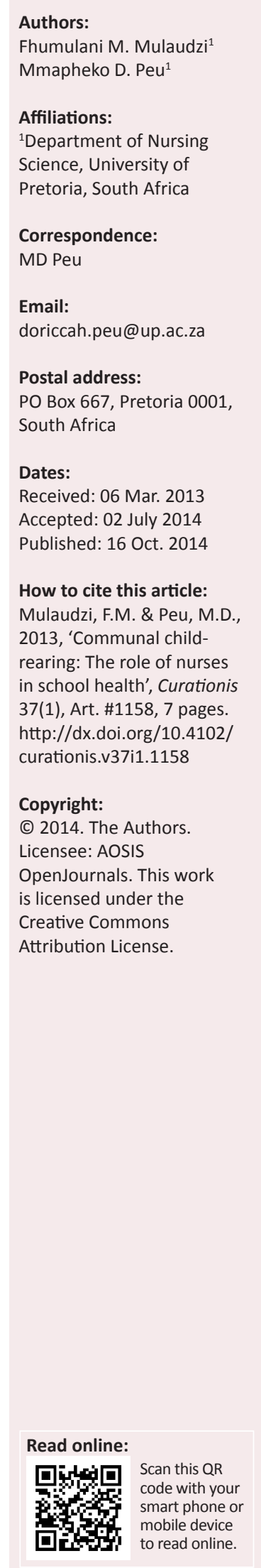

Background: Child-rearing remains a concern within our communities, especially because families of today lack primary parents due to multifaceted challenges such as working mothers, diseases and violence. Health-promoting school initiatives are necessary because they allow a multifaceted approach to child-rearing. They further provide a conducive environment for continued schoolchild-rearing moving from home to school.

Objectives: This study promotes an integrated approach to school care using the African concept of Ubuntu - solidarity and sense of community - as a point of departure. The socioecological model was used, which includes the work of the school healthcare nurse in contributing to holistic health services.

Method: An integrative review was conducted in January 2013, which included methodology studies, a theory review and a variety of studies related to school health. The studies were categorised according to school health, Ubuntu and the socio-ecological model.

Findings: The role of school healthcare nurses entails acting as a liaison officer between a variety of stakeholders who work together to shape the future of children.

Conclusion: Ubuntu, together with the socio-ecological model, can assist us to involve an entire community to raise children. This knowledge serves as a background to the planning of a school health programme. The role of the nurse in school health can also assist in collaborative efforts to formulate the programme and develop the competencies that will inform school health nurse training curricula.

\section{Introduction}

In this article we argue that communal child-rearing is essential within diverse communities, and child-rearing occurs within internal and external environments. We use the African proverb 'umuntu ngumuntu ngabantu' [a person is a person through other persons], which has the involvement and role of the wider community in raising a child as a premise. In today's challenging environment the parents or school as separate entities will not be able to raise children alone, and provide all of the services and meet all of the needs to ensure that children thrive and develop as envisaged (Haynes et al. 1996:43). We argue that we need coordinated efforts to be able to design a functional and integrated school health programme.

\section{Problem statement}

As in other developing countries, school health care programmes in South Africa are faced with multifaceted challenges that entail educational, physical, psychological, spiritual and economic dimensions. The school remains a critical environment for preventive and promotive health (Whitehead 2006:265). Like a village, a school is an environment where socialisation, nurturing, support and encouragement of children take place (Palmer \& Gasman 2008:66). Children learn their life skills at school. They need an enabling environment that allows them to develop in terms of learning styles, eating habits, hygiene, exercise, play and other habits that constitute holistic development. The morals and values that children learn during their school years from their families, community and school have an influence on their future endeavours.

The authors have observed that the nurse has a pivotal role to play in school health care, to instil healthy behaviour and practice that will assist in shaping the future of children (National Association of School Nurses 2013). Dreyer (2007:5) argues that the more children feel valued and appreciated in their communities, the more they will contribute to development of their nation. Haynes et al. (1996:42) argue that children value a school environment in which they 'feel part of a very special loving family that faces adversity every day and reaffirms every day that the next day will be better for all.' 
It is therefore eminent that an integrated approach amongst different stakeholders is needed to ensure that the country has a well-established school healthcare system that is affordable, accessible, sustainable and acceptable to all (Haynes et al. 1996:6). In support of this idea, the South African Integrated School Health Policy (Departments of Health [DoH] \& Department of Basic Education [DBE] 2012:10) was developed with the objective of promoting optimal health and developing school-going children and the communities in which they live and learn. This policy also emphasises provision of health services that are available and affordable, and focuses on achievement of good health and education outcomes (DoH \& DBE 2012:8-9; Fisher et al. n.d.).

\section{Aim of the study}

The aim of the study is to describe communal child-rearing as the role of the school health nurse, with an emphasis on the African proverb Ubuntu as motivation for development of an integrated approach to school health.

\section{Background}

Central to the model, programme and philosophy is the notion of teamwork and coordination for development of the school healthcare system in South Africa. This view is echoed by Haynes et al. (1996:3), who assert that it is important to rebuild the community and create a network of service with the school at the centre. Unlike other work which has been done in school health, our work has adapted or is underpinned by the philosophy of Ubuntu. Ubuntu demands contextual inclusiveness and cohesiveness of teamwork, in this case in rearing of a child. The work also included an ecological model (Robinson 2008:397) and the multiple intervention programme framework. The two emphasise multilevel approaches in strengthening teamwork and coordination amongst different sectors (Edwards, Mills \& Kothari 2004:402). These three - Ubuntu, the socio-ecological model and multiple intervention framework - establish a synergy that can be used as a point of departure to facilitate the coordinated effort of designing an effective programme.

The vision of the Integrated School Health Policy (DoH \& DBE 2012) indicated that the focus of school health programmes should be on the optimal health and development of school-going children and the communities in which these children reside. The policy further emphasises the roles of other sectors, including the school health sector, in the development of schoolchildren. This shows that development of children cannot be separated from their schooling - they should be treated as a package.

Rowe et al. (2005:512) had a similar and supportive notion, and alluded that if implemented correctly maternal schooling can improve maternal and child health, thus decreasing child mortality and enhancing further child development through integrated approaches. Rowe et al. (2005:530) further noted that socio-economic control variables such as schooling, household wealth and rural residence determine health behaviour rather than health knowledge. Therefore maternal schooling needs local knowledge of the indigenous culture in order to learn more about health practices.

\section{Research method and design}

An integrative literature review was conducted in order to focus on the identified topic. An integrative literature review is regarded as a distinctive form of research, which produces knowledge about the topic of interest (Torraco 2005). This method allowed for inclusion of diverse methodologies. The integrative literature review was conducted on available and related literature on school health, Ubuntu philosophy, socioecological model, monitoring and evaluation, and strategies for implementation of school health services, providing the basis for critical discussion and recommendations.

First the topic was identified and literature was searched through the University of Pretoria database, Allied Health Literature, CINAHL, ebscohost, Google, and other diverse sources. The studies were categorised according to school health, Ubuntu philosophy, socio-ecological model, monitoring and evaluation, and strategies for implementation of school health services. Each article was carefully selected and validated. The results were interpreted and summarised.

\section{Results and discussion}

The discussion of results will focus on the Ubuntu philosophy, socio-ecological model, multiple intervention programmes, school health services, monitoring and evaluation, and strategies for implementation of school health services.

\section{The philosophy of Ubuntu}

The African proverb 'it takes a village to raise a child' emanates from the principle of Ubuntu. Ubuntu philosophy finds expression in the African idiom 'umuntu ngumuntu $n g a b a n t u$ ', which translates into 'a person is a person because of other persons'. The emphasis of the idiom is that you need other people to be recognised as a person. It emphasises interrelationships and interdependency between human beings.

It is noted that a person with Ubuntu is always open to and available for others (Tutu 1999), especially in response to the needs of others. Jackson (2010) supports the definition by adding that Ubuntu is a philosophy that supports the changes necessary to create a future that is economically and environmentally sustainable. Nkondo (2007:98-99) also mentioned that universities are expected to educate, transmit, interpret and develop Ubuntu principles and values in order to nurture political consciousness of students. Nkondo (2007:99) further expressed that new institutional frameworks should be developed to destroy the old way of doing things, and new strategies based on Ubuntu principles should be built. It is therefore concluded that a person is never complete until a person is amongst others 
to fulfil needed actions. In taking a child to school, a team of stakeholders is needed to protect this child along the path of an academy, with various principles and efforts required to maintain the efforts of the group.

The principles of Ubuntu are solidarity, participatory decision-making, sense of belonging and consensus. The African proverb of 'it takes a village to raise a child' is based on the principle of collaboration and solidarity. The emphasis of collaboration and solidarity is on teamwork between different stakeholders to raise a child. As already indicated, the problems of the children are multifaceted, and they therefore need concerted efforts based on collaboration amongst parents, school teachers, social workers, psychologists, pastors and business.

The philosophy of Ubuntu also emphasises a sense of belonging, ensuring that the school environment is viewed as a place where children interact with others. Haynes et al. (1996:47) point out that schools are a place where emphasis can be put on promotion of the community's economic advancement, regeneration of the moral fabric of society, and improvement of the psychological and social health of the future generations. Ubuntu emphasises the caring which is based on affirming the existence of others and understanding the interrelationships between individuals. Cohesiveness is emphasised and leads to good relationships based on respect and trust (Mulaudzi, Libster \& Phiri 2009). Community members feel obliged to instil moral values into the children in the community, and that creates a neighbourhood where children feel safe and secure.

The school healthcare nurse's role is to create and promote safe and secure school environments characterised by respect and trust (Chong 2007:1823). Historically school health nurses were expected to provide nursing services in non-health and non-nursing settings with the aim of preventing diseases, promoting health and curing illnesses (Lundy \& Janes 2001:924).

Schools have replaced village life where children were socialised, raised and taught good manners, values and morals through mentoring and role-modelling. In villages programmes such as sexuality education were taught in initiation schools, as they occur during different stages of growth. Exercises were done and encouraged through different types of traditional dancing, forms of play and also the type of work that people did, such as fetching water from faraway places and carrying and chopping wood. People ate nutritious food, whilst overeating was discouraged. Information such as health education was relayed and shared through songs. All activities that formed part of village life are currently being offered at schools. Therefore the village and school lives should collaborate and be coordinated in a harmonious relationship in order to sustain Ubuntu and the good practices inherent within village communities.

There is an international perspective on triage and school preparedness regarding unforeseen emergency incidents.
If not well planned for, such incidents may take away the notion of Ubuntu as the foundation for good practice. This international perspective includes triaging during disasterpreparedness. In addition, in order to ensure an Ubuntu environment the school component should be well prepared to adjust to an emergency when any type of disaster occurs. The preparedness should involve school components such as teachers, the School Governing Body, parents and learners. The Illinois Department of Public Health (2006) provides a document for conducting disaster drills in an effort to assist in preparing an organisation to manage very ill and injured children during an actual disaster. It is therefore necessary for South African schools to prepare triaging and disasterpreparedness in order to uplift the Ubuntu notion.

Although Ubuntu recognises that an individual is a unique being, the emphasis is on neighbourliness, which highlights ability to share resources and encourages the spirit of giving to those in need. In turn, those who are in need of care are socialised in such a way that they learn the same from others. In this case different stakeholders feel responsible and exercise Ubuntu by assisting in school health by providing different services, which may be physical, social, psychological or socio-economic. The phenomenon is supported by Putnam (2000:277), who views the act of caring, giving and neighbourliness and caring for children (including those who are not your own) as social capital. The discussion further reminds individuals that Ubuntu is priceless, earned and not forcefully claimed.

The Ubuntu principles may be synergised with multiple intervention programmes, which also emphasises coordinated, interconnected interventions aimed at improving health by making changes to more than one level of a socio-ecological system. The role of a nurse is to act as a liaison officer who ensures that all the pieces of the puzzle fit together in ensuring coordinated school healthcare services.

\section{Socio-ecological model}

The socio-ecological model describes the relationship between health behaviour and social organisation at the interpersonal, organisational, community and policy levels. The socio-ecological model addresses health promotion from a different perspective which emphasises interrelatedness between determinants of health care, such as social, economic, political and cultural factors (Kothari et al. 2007; Edwards et al. 2004:41). According to Sallis and Owen (1997:404) 'The model helps us to understand how people behave within the environment.' The understanding assists us to tackle problems using a multilevel approach. Different stakeholders are involved from multiple levels.

At the intrapersonal level the individual's health is influenced by demographics, biological and psychological factors (Sallis \& Owen 1997:404). These factors are usually beyond the level of the individual herself. At the same time, the attitudes and skill of the individual are important as they determine how the nurse will respond to health education 
and activities related to health and wellness. The attitude of an individual determines their perception of health care. However, Mulaudzi et al. (2009:46) point out that an individual who embraces Ubuntu feels and thinks about herself and her own health behaviour in relation to others. Her view is about how others are going to benefit or how their decision is going to affect the significant other. A nurse must be able to plan services that will accommodate different individuals and their similarities as well as their differences. She must be aware of the environment in which she operates to be able to intervene appropriately. The lifestyle choices that children make may be influenced by other determinants, such as the environment or the politics of the country.

Interpersonal level factors involve the primary social relationships surrounding an individual and her relationship with friends, family and co-workers. In this case the stages of development also play a role. The school nurse must plan services in consultation with the family and community. The services designed for teenagers must accommodate factors such as peer pressure, mob psychology, et cetera, which can affect the acceptability of and buying-in to services. It is therefore the responsibility of the school nurse to plan services that involve group work, discussions and role-play.

\section{The environment}

The physical environment of the school has a bearing on the health of children. The environment may either expose children to health hazards such as pollution and lead poisoning whilst on the positive side it may be conducive to their healthy status, where they are exposed to physical exercise and a healthy diet (Grywacz \& Fuqua 2000:104). The school health nurse has to be aware of the psychological and social aspects of the school environment in order to be able to make evidence-informed interventions.

\section{Institutions and organisations}

Institutions and organisations play a pivotal role in the provision of school health services. As outlined during the Alma Ata Declaration (Dennill, King \& Swanepoel 2008:2-4), intersectoral collaboration is an answer to accessible and available primary health care (Dennill et al. 2008:2-4). Community groups, organisations and institutions are usually willing to be involved in school healthcare services. They gain from their involvement and view it as a marketing strategy and community engagement activity. Haynes et al. (1996) summarises it as follows:

\footnotetext{
In the long run they benefit by helping to produce healthy and well-educated, intelligent, creative, and productive citizens who becomes members of the labour force, community leaders, business executives, and responsible heads of households. Indeed the whole community and entire country benefit from a coordinated and integrated approach of services and education to children and families. (p. 53)
}

\section{Multiple intervention programmes}

Multiple intervention programmes (MIPs) have multiple components with interconnected intervention strategies, and are targeted at multiple interventions in a system (Edwards et al. 2004:402). The emphasis is was on the need for coordination and interconnectedness between health facilities, family, community, working places, industry and schools. In turn the socio-ecological model approach in health promotion views health as a product of the interdependence between the individual and subsystems of the ecosystem: family, community, culture, and the physical and social environment (Green \& Kreuter 1999).

The emphasis of the MIP is on understanding that there are multiple layers in an institution which are all equally important and valuable to sustain a programme. In this case, for school health care to succeed the family, community, non-governmental organisations, business sector, the church and different departments in government are needed to make it a success.

Edwards et al. (2004) designed a multiple intervention framework that describes how MIPs can be used for planning and evaluation of programmes. The framework entails describing the socio-ecological features of the public health problem, identifying intervention options, optimising potential impact and monitoring the process, impact and spin-offs. This framework can be used to plan, monitor and evaluate the school health programme.

\section{School health services}

Based on the synergistic models which emphasise collaboration, the school health service can be defined as a health-promotive service dealing with the individual in the context of the family and community and within the school environment. Haynes et al. (1996:3) state that the school has the power to facilitate the student's attainment of the well managed self that is engendered by the strengthening of linkages amongst all of the development pathways.' The service encourages the school to seek to develop and implement school policies that promote and sustain health, improve the physical and social environment within which children learn and develop, and improve children's capacity to become and stay healthier. In support of the above statements, the South African Government has taken a pledge which reads as 'put children first' (DoH \& DBE 2012:6). The policy focuses on optimal health and development of the general health of school-going children, including their environments. In the same policy it is emphasised that the Integrated School Health Programme is part of the comprehensive primary healthcare package which should be available and applied to all schools. The Integrated School Health Policy (DoH \& DBE 2012:10) shows that the South African Government is a caring and supportive system that is essential to all.

The School health service is expected to provide healthpromoting services by acting in a coordinating role, making use of skills and capacity in different sectors of society, including the community, the learners themselves, educators and non-governmental organisations. The school 
health teams are becoming an integral part of primary health care. This notion was emphasised during the Alma Ata Declaration conference held in 1978, where various countries agreed that there should be equity, intersectoral collaboration, community involvement and participation (Dennill et al. 2008:2-4). During that year emphasis was on working collaboratively in reaching common goals.

The school healthcare services entail: (1) health services; (2) health education; (3) efforts to ensure healthy physical and social environments; (4) nutrition services; (5) physical education and other physical activities; (6) counselling, psychological, and social services; (7) health programmes for faculty and staff; and (8) collaborative efforts of schools, families, and communities to improve the health of students. In execution of the above activities, school health nurses are expected to be skilled and knowledgeable, with a positive attitude. They are required to provide the services within their scope of practice as outlined by the Nursing Act No. 33 of 2005 (South African Nursing Council 2005).

\section{Role of the nurse in school health}

The school nurse is a liaison person between schoolchildren, families, community organisations and policy makers. She advocates for the health of the schoolchildren by collaborating with different stakeholders who assist in upliftment of the activities in school health care. The role has expanded from health education in school to provision of integrated holistic healthcare services which include physical, spiritual, psychological and educational, facilitative, administrative and socio-economic dimensions. It is clearly stated in the American Academy of Pediatrics document (2008:1053) that a school health nurse has a unique role in providing school health services to children with special health needs. The document further emphasises that a school health nurse as a leader and member of the team should conduct health assessment and reach diagnoses that will inform the learners' healthcare plan.

The role of the nurse in school health is critical, as she is the person who is expected to integrate all of the services. Nurses must perceive the opportunity of planning and implementing the school healthcare system as an opportunity to exercise leadership in nation building and collaboration efforts towards a healthy nation. Principles of Ubuntu must be used as the basis of caring, whilst the philosophy acts as a foundation that influences the vision and mission of our programmes. The African philosophy is commensurate with the socio-ecological model, which emphasises that schoolchildren's lives must be understood from different levels, such as the intrapersonal, organisational and policy level.

The school nurse liaises between school personnel, family, healthcare professionals and the community (Wolfe 2006). According to the Integrated School Health Policy (DoH \& DBE 2012:20) the school health nurse is a professional nurse responsible for facilitation of the policy. This nurse is also responsible for a variety of activities. She has to be a competent nurse who is able to assess, diagnose, plan, teach, promote, consult, evaluate, educate and collaborate with others. The nurse should be involved in research, planning, implementing, utilisation of resources and fostering collegiality. She has an important role to play in using competencies, and also should be a competent clinician who will be able to assess, diagnose, plan care and refer to appropriate services. Based on her expertise the nurse is able to conduct research and provide evidence-based information which can be formulated and translated to school policies. The nurse may be involved in implementation, monitoring and evaluation of the school health policies and other relevant policies which impact on school health services.

The school health service is governed by the National School Act No. 27 of 1996 (National Department of Education 1996) and other school health policies. These policies include health promotion and protection, chronic disease management, coordinated school health programmes, school wellness policies, crisis/disaster management, emergency medical condition management, mental health protection and intervention, acute illness management, and infectious disease prevention and management. Research plays a very important role as it provides information and evidence which informs the curricula and improvement and changes in provision of healthcare services. She is a team player who is involved at multiple levels.

The role involves being able to build relationships with stakeholders. She has to be able to build trust with children, parents, teachers and many different stakeholders. Networking through involvement in school activities and using electronic social media such as Skype, Facebook and Twitter will assist the nurse to break barriers between herself and the children.

Planning is also a required competency skill. The philosophy of Ubuntu emphasises the need for involvement and mutual respect. The skill adopted from the philosophy can be utilised to engage all stakeholders in planning sessions. There is a need to adhere to the inputs of stakeholders from all levels. Collaborative efforts will also assist in ensuring empowerment and sharing of expertise and skills amongst different stakeholders involved (Haynes et al. 1996:45).

\section{Monitoring and evaluation mechanisms}

Monitoring and evaluation are needed within the school health environment and they need to be nurtured and sustained. In monitoring and evaluation the school health team needs to be well trained and fully empowered. The system is logical and consistent to ensure user-friendly school health services. The school health team could use various mechanisms in monitoring and evaluation. According to the Integrated School Health Policy (DoH \& DBE 2012:21) monitoring and evaluation should focus on provision of services, quality and coverage of the services, and their impact on learners, especially their retention and 
achievement. The policy further covers the sustainability of school health services in various districts. The school health nurse should be updated with all these skills in order to sustain appropriate and relevant services for the learners.

\section{Strategies for implementation of school health services}

There are strategies that could be used in the implementation of school health services. These strategies include, amongst others, MIPs, as discussed in the previous sections. The MIPs, as indicated earlier, have multiple components with interconnected intervention strategies and are targeted at multiple interventions in a system (Edwards et al. 2004). It was further indicated that the emphasis was on the need for coordination and interconnectedness between health facilities, family, community, working places, industry and schools, including the socio-ecological model approach in health promotion. Other strategies include research advocacy programmes, behaviour change communication, capacity building, resource mobilisation, networking and participation. Research advocacy is where the researcher will advocate and protect the participants and respondents ethically to ensure their safety in the school environment. Behaviour change through communication plays an important role, because we expect the school health nurse through their expertise to change the health behaviour of learners through health education. During these interactions capacity building, networking and participation are ensured through cost-effective mobilisation.

\section{Limitations of the study}

The information from the studies referred to in this article cannot be generalised. It has been found that there are limited studies focusing on communal child-rearing as the role of the school health nurse with emphasis on the African philosophy of Ubuntu. Therefore empirical studies focusing on Ubuntu, child-rearing and school health nurses may be conducted to enhance the integrated approach to school health.

\section{Conclusion}

It has been noted in this article that the connotation of a 'village' was predominantly African, as this idiom is African in nature. It also indicates how children are reared in a communal community. In conclusion, this article calls for more, strong and sustained collaboration in terms of school health. The partnership should work closely with community stakeholders to promote the health of children and youth as education assets. The school health nurse can act as a broker to ensure that all sectors are involved in planning, organisation, implementation and monitoring and evaluation of the process. There is a Venda proverb which says 'munwemuthihi a u tusimathuthu' [one finger will not be able to pick a grain of rice]. In Zulu they say 'Izandlaziyagezana' [hands wash each other].

In order for collaboration to take place within the school environment there is a need for solidarity and cohesiveness.
The role of the nurse in school health is pivotal and critical in nature. The nurse has to think on her toes, be innovative, creative, and humble yet honourable. A possible direction for further research which is important for future child development is traditional schoolchild-rearing versus Western schoolchild-rearing.

\section{Acknowledgements}

The authors would like to acknowledge the University of South Africa and Department of Health for providing us with the opportunity to submit this article.

\section{Competing interests}

The authors declare that they have no financial or personal relationship which may have inappropriately influenced them in writing this article.

\section{Authors' contributions}

F.M.M. (University of Pretoria) and M.D.P. (University of Pretoria) equally contributed to the research and writing of this article.

\section{References}

American Academy of Pediatrics, 2008, The role of the school health nurse in providing school health services, viewed 17 June 2014, from http://pediatrics. aappublications.org/content/121/5/1052.full.html

Anon, n.d., Health promotion and education, viewed 21 January 2013, from http:// www.enotescom/health-promotion-education-reference/health-promotioneduc

Chong, S.T., 2007, 'It takes a village to raise a child: Building social capital in safe and cohesive neighbourhood', Journal e-Bangi 2(2), 1823-1884.

Dreyer, J., 2007, Purpose: It takes a village, viewed 02 October 2013, from www. passionatelycurious.com/.../dreyer-purpose4.pdf

Edwards, N., Mills, J. \& Kothari A.R., 2004, 'Multiple intervention research programs in community health', Canadian Journal of Nursing Research 36, 40-54.

Dennill, K., King, L. \& Swanepoel, T., 2008, Aspects of primary health care, Oxford University Press, Cape Town.

Fisher, C., Hunt, P., Kann, L., Kolbe, L., Patterson, B. \& Wechsler, H., n.d., Building a healthier future through school health programs, viewed 02 October 2013, from www.cdc.gov/healthyyouth/publications/pdf/PP-Ch9.pdf)

Green, L.W. \& Kreuter, M.W., 1999, Health promotion planning: An educational and ecological approach, pp. 20-26, McGraw Hill, New York.

Grywacz, J.C. \& Fuqua, J., 2000, 'The social ecology of health: Leverage points and linkages', Behavioral Medicine 26, 101-115. http://dx.doi. org/10.1080/08964280009595758

Haynes, N.M. , Ben-Avie, M., Squires, D.A., Howley, J.P., Negron, E.N. \& Corbin, J.N., 1996, in J.P. Comer, H.M. Norris, E.T. Joyner \& M. Ben-Avie (eds.), Rallying the whole village: The Comer process for reforming education, pp. 42-71, Teachers College Press, New York.

Illinois Department of Public Health, 2006, Disaster preparedness exercises addressing the pediatric population, Loyola Medicine, Illinois, viewed 21 January 2013, from www.luh.org/emsc

Jackson, T., 2010, Tim Jackson Economic Reality Check Speech, viewed 09 December 2010, from http://www.ted.com/talks/tim-jackson-s-economic-reality-check

Kothari, A., Edwards, N., Yanicki, S. \& Hansen-Ketchum, P., 2007, Sociological models: Strengthening intervention research in tobacco control, Drogues, Sante et Sociĕtĕ, 6(1 suppl 3):1-24.

Lundy, K.S. \& Janes, S., 2001, Community Health Nursing: Caring for public's health, Boston, Jones \& Barlett.

Mulaudzi, M., Libster, M. \& Phiri, S., 2009, 'Suggestions for creating a welcoming nursing community: Ubuntu, cultural diplomacy, and mentoring', International Journal of Human Caring 13(2), 46-52.

National Association of School Nurses, 2013, Coordinated School Health: Position Statement, viewed 02 October 2013, from www.nasn.org

National Department of Education, 1996, National Education Policy Act, Act 27 of 1996, Government Printers, Pretoria.

National Department of Health and National Department of Basic Education, 2012, Integrated School Health Policy, Government Printers, Pretoria. 
Nkondo, G.M., 2007, 'Ubuntu as a public policy in South Africa: A conceptual framework', International Journal of African Renaissance Studies 2(1), 88-100.

Palmer, R.T. \& Gasman, M., 2008, 'It takes a village to raise a child: The role of socia capital in promoting academic success for African American men at a black college', Journal of College Student Development 49(1), 51-70. http://dx.doi. org/10.1353/csd.2008.0002

Putnam, R., 2000, Bowling alone: The collapse and revival of American community, Simon \& Schuster, New York.

Robinson, T., 2008, 'Applying the Socio-ecological Model to improving fruit and vegetable intake among low-income African Americans', Journal of Community Health 33, 395-406. http://dx.doi.org/10.1007/s10900-008-9109-5

Rowe, M.L., Thapa, B.K., Levine, R., Levine, S. \& Tuladhar, S.K., 2005, 'How does schooling influence Martenal health practices? Evidence from Nepal', Comparative Education Review 49(4), 512-533. http://dx.doi.org/10.1086/432769
Sallis, J.F. \& Owen, N., 1997, 'Ecological models', in K. Glanz, F.M. Lewis \& K. Rimer (eds.), Health behaviour and health education: Theory research and practice, $2 \mathrm{nd}$ edn., Jossey Bass, San Franscisco.

South African Nursing Council, 2005, Nursing Act, Act 33 of 2005, South African Nursing Council, Pretoria.

Torraco, T., 2005, Writing integrative literature reviews: Guidelines and examples, viewed 17 October 2012, from http://hrd.sagepub.com/content/4/3/356

Tutu, D., 1999, No future without forgiveness, Random House, New York.

Whitehead, D., 2006, 'The health-promoting school: What role for nursing?', Journal of Clinical Nursing 15, 264-271. http://dx.doi.org/10.1111/j.1365 2702.2006.01294.x

Wolfe, L.C., 'Role of the school nurse', 2006, in J. Selemank (ed.), School Nursing: $A$ Comprehensive Text, pp. 111-127, F.A. Davis, Philadelphia, PA. 